Importance of Driving and Potential Impact of Driving Cessation for Rural and Urban Older Adults

David Strogatz, PhD; ${ }^{1}$ Thelma J. Mielenz, PhD; ${ }^{2,3}$ Andrew K. Johnson, $\mathrm{BS} ;{ }^{1}$ Ida Baker, MA; ${ }^{1}$ Melinda Robinson, BS; ${ }^{1}$ Sean P. Mebust; ${ }^{1}$ Howard F. Andrews, PhD; ${ }^{2,4}$ Marian E. Betz, MD, MPH; ${ }^{5}$ David W. Eby, $\mathrm{PhD} ;^{6,7}$ Renee M. Johnson, $\mathrm{PhD} ;^{8}$ Vanya C. Jones, $\mathrm{PhD} ;{ }^{8}$ Cheng Shiun Leu, $\mathrm{PhD} ;^{2}$ Lisa J. Molnar, $\mathrm{PhD} ;{ }^{6,7}$ George W. Rebok, PhD; ${ }^{8}$ \& Guohua Li, MD, $\mathrm{DrPH}^{2,3,4}$

${ }^{1}$ Bassett Research Institute, Cooperstown, New York

${ }^{2}$ Mailman School of Public Health, Columbia University, New York, New York

${ }^{3}$ Center for Injury Epidemiology and Prevention, Columbia University, New York, New York

${ }^{4}$ Columbia University College of Physicians and Surgeons, New York, New York

${ }^{5}$ School of Medicine, University of Colorado, Aurora, Colorado

${ }^{6}$ University of Michigan Transportation Research Institute, Ann Arbor, Michigan

${ }^{7}$ Center for Advancing Transportation Leadership and Safety, University of Michigan, Ann Arbor, Michigan

${ }^{8}$ Bloomberg School of Public Health, Johns Hopkins University, Baltimore, Maryland

Disclosures: The authors have no competing interests. The funders of this study had no role in the design and conduct of the study; the collection, management, analysis and interpretation of the data; the preparation, review or approval of the manuscript; and the decision to submit the manuscript for publication.

Funding: This study was supported by the American Automobile Association Foundation for Traffic Safety.

Acknowledgements: We are grateful for the contributions from colleagues of the LongROAD Study Research Team - Drs. Carolyn DiGuiseppi, Linda Hill, and Lindsay Ryan.

For further information, contact: David Strogatz, PhD, Bassett Research Institute, One Atwell Road, Cooperstown, NY 13326. Email: david.strogatz@bassett.org.

Running Head: Rural-Urban Differences for Older Adult Drivers

Key Words: aging, driving cessation, older drivers, rural, urban

This is the author manuscript accepted for publication and has undergone full peer review but has not been through the copyediting, typesetting, pagination and proofreading process, which may lead to differences between this version and the Version of Record. Please cite this article as doi:10.1111/jrh.12369.

This article is protected by copyright. All rights reserved. 


\title{
Importance of Driving and Potential Impact of Driving Cessation for Rural and Urban Older Adults
}

\begin{abstract}
Purpose: Analyses compared older drivers from urban, suburban, and rural areas on perceived importance of continuing to drive and potential impact that driving cessation would have on what they want and need to do.

Methods: The AAA LongROAD Study is a prospective study of driving behaviors, patterns, and outcomes of older adults. A cohort of 2,990 women and men 65-79 years of age was recruited during 2015-2017 from health systems or primary care practices near 5 study sites in different parts of the United States. Participants were classified as living in urban, surburban, or rural areas and were asked to rate the importance of driving and potential impact of driving cessation. Logistic regression models adjusted for sociodemographic and driving-related characteristics.
\end{abstract}

Findings: The percentages of older drivers rating driving as "completely important" were 76.9\%, 79.0\%, and $83.8 \%$ for urban, suburban, and rural drivers, respectively $(P=.009)$. The rural drivers were also most likely to indicate driving cessation would have a high impact on what they want or need to do $(P<.001)$. After adjustment for sociodemographic and driving-related characteristics, there was a twofold difference for rural versus urban older drivers in odds that driving cessation would have a high impact on what they need to do (OR=2.03, 95\% Cl: 1.60-2.58).

Conclusions: Older drivers from rural areas were more likely to rate driving as highly important and the prospect of driving cessation as very impactful. Strategies to enhance 
both the ability to drive safely and the accessibility of alternative sources of transportation may be especially important for older rural adults.

Key Words: aging, driving cessation, older drivers, rural, urban

The influence of driving on the well-being of older adults has been documented in multiple studies demonstrating declines in social engagement, cognitive and physical function, and survival following driving cessation. ${ }^{1-5}$ The motivation to continue driving may be especially pronounced for older adults in rural areas because of limited options for public and other alternative sources of transportation and the longer distances between regular destinations such as grocery stores, pharmacies, health care providers, and locations for social activities. ${ }^{6-9}$ As a result, older rural drivers may be more likely than urban drivers to continue driving despite various physical and cognitive limitations. ${ }^{6}$

Some research has suggested that increased physical and cognitive limitations in rural older drivers are a contributing factor for their increased risk of severe injuries from crashes compared to their urban counterparts. ${ }^{10,11}$ However, subsequent analyses revealed that aspects of the rural driving environment (eg, undivided, unsealed, and curved roads) predicted increased injury severity from crashes for rural drivers of all ages, so that environmental factors might be more important for understanding rural-urban differences in crash-related outcomes. ${ }^{12}$ In an analysis limited to Texas drivers injured in crashes between 1975 and 1999, impairment due to illness or a physical limitation was more common for injured drivers from rural versus urban areas, though the percentages of impairment were fairly low (eg, $2 \%$ for injured rural drivers at age $70,3 \%$ at age 80$).{ }^{13}$ In other studies of older adults from rural and urban areas that have measured functional factors and driving status, the results have not been presented in a format that allows 
comparison of the functional status of rural and urban drivers. ${ }^{14,15} \mathrm{O}^{\prime}$ Connor and associates ${ }^{4}$ provided cross-sectional data indicating that measures of balance and physical and social functioning were more predictive of driving versus not driving for older adults from large cities, but the comparison was with smaller cities ( $<250,000$ population), not rural areas. The American Automobile Association (AAA) LongROAD Study ${ }^{16}$ included participants from rural, suburban, and urban areas; therefore, it provides a more direct opportunity to evaluate whether there are geographic differences in attitudes about driving and the physical, sensory, and cognitive abilities of older drivers. The initial research questions addressed in these analyses are as follows: Do older adult drivers from urban, suburban, and rural areas differ in rating the importance of continuing to drive? Do older adult drivers from urban, suburban, and rural areas differ in rating the potential impact that driving cessation would have on what they want and need to do in their lives?

\section{Methods}

The AAA LongROAD Study is a prospective cohort study of personal, vehicular, and environmental factors that predict the driving behaviors, patterns, and outcomes (eg, crashes, convictions) of older adults who currently drive on average at least once a week. A total of 2,990 women and men 65-79 years of age were recruited during July 2015 to March 2017 from health systems or primary care practices near 5 study sites (Ann Arbor, MI; Baltimore, MD; Cooperstown, NY; Denver, CO; and San Diego, CA). Criteria for eligibility included having a valid driver's license; driving on average at least once a week and using one vehicle at least $80 \%$ of the time; and residing in the study area for at least 10 months each year. Baseline data collection included interviewer-administered questionnaires, 
functional performance tests, and vehicle inspections. Additional details regarding the study design and methods are described elsewhere. ${ }^{16}$

The data for these analyses were collected from the interviewer-administered questionnaires at the baseline visit of all participants. The importance of driving and the potential impact of driving cessation were based on responses to the following questions:

- "How important is driving to you?"

- "If you could not drive, how much would it affect what you want to do?"

- "If you could not drive, how much would it affect what you need to do?"

The response options for these questions ranged from 1 to 7 , with 1 labeled as "not at all" and 7 labeled as "completely." For each of the 3 questions, "completely" was the modal response. In the analyses, high importance of driving and high impact of driving cessation were classified as yes (response option 7) or no (response options 1-6).

The designation of urban or rural residence was based on the Rural Urban Commuting Area (RUCA) values for ZIP Codes of study participants. ${ }^{17}$ Over two-thirds of LongROAD study participants lived in the core region of metropolitan statistical areas (RUCA codes 1.0 and 1.1). Two smaller categories of participants were defined by residence within the non-core region of a metropolitan statistical area (RUCA codes 2.0, 2.1, 3.0) and by residence in non-metropolitan areas (RUCA codes $>3$ ). Following similar logic and nomenclature used in a Pew Research Center report, ${ }^{18}$ these 3 RUCA categories are referred to as urban, suburban, and rural, respectively.

Sociodemographic characteristics recorded at the baseline visit and included in the analyses were age, gender, marital status, race and ethnicity, educational attainment, household income, and whether the participant was employed for pay and/or involved with volunteer work. In addition to the questions about importance of driving and potential 
impact of driving cessation, participants were asked: how many days they drove in a typical week; how many miles they drove on most trips out and back from home; the other forms of transportation recently used (in addition to driving oneself); whether a friend or family member was available to give them rides; and whether there was someone who depended on them for driving. These sociodemographic and driving-related characteristics were included in the analyses as variables that might vary across RUCA categories and help explain differences in the ratings of driving importance and the potential impact of driving cessation.

A chi-square test statistic was computed for the bivariate analyses of the RUCA categories with the importance of driving and the 2 measures of impact from driving cessation. To further assess whether high ratings for importance of driving and for potential impact of driving cessation varied by RUCA categories, logistic regression models were computed separately for each outcome measure. Odds ratios and $95 \%$ confidence intervals are reported for the RUCA categories, with the urban category serving as the referent. The models also adjusted for the sociodemographic and driving-related variables.

\section{Results}

Sociodemographic and driving characteristics of the AAA LongROAD study population by RUCA categories are summarized in Table 1. Residents of urban areas were more likely to be college graduates and have higher levels of income. The race and ethnicity of the study population was predominantly white and non-Hispanic, especially beyond the urban areas. The percentage of participants who reported normally driving each day of the week was approximately similar across the 3 RUCA categories. Residents of the suburban and rural areas had a higher percentage of most trips from home being longer than 15 miles. Recent 
use of alternative forms of ground transportation was more common in urban areas.

Virtually all participants, regardless of area of residence, indicated that a friend or family member was available to give them a ride.

Responses to the survey questions on importance of driving and potential impact of driving cessation are shown in Figure 1. Driving was rated as highly important by over $75 \%$ of study participants, increasing from $76.9 \%$ for residents of urban areas to $79.0 \%$ of suburban drivers and $83.8 \%$ of rural drivers $\left(X^{2}=9.37, P<.01\right)$. The majority of older drivers living in rural areas predicted high potential impact of driving cessation on what they would want to do (60.2\%) or need to do (53.8\%); these percentages were significantly higher $\left(X^{2}=36.78\right.$ and 43.08 for want and need, respectively, $\left.P<.001\right)$ than the responses from the older drivers of urban $(43.8 \%, 36.3 \%)$ and suburban $(49.2 \%, 40.2 \%)$ areas.

Logistic regression models were designed to specifically contrast suburban and rural residents with those who live in urban areas, while adjusting for sociodemographic and driving-related characteristics that may also potentially predict importance of driving and impact of driving cessation. The results of the logistic models are summarized in Table 2. Among the sociodemographic characteristics, the importance of driving and potential impact of driving cessation were stronger for women than men but less important and impactful for married than non-married participants. The impact of driving cessation was also inversely related to years of education. Older adults still working for pay reported that driving cessation would specifically impact what they needed to do.

Driving frequency and miles driven on most trips from home were both directly related to importance of driving and the potential impact of driving cessation, while importance and potential impact tended to be lower among recent users of the alternate forms of transportation. The potential impact of driving cessation was less if a friend or 
relative was available to provide rides, but greater for participants who served as the driver for someone else. Finally, the greater importance of driving and potential impact of driving cessation that was observed for rural residents in Figure 1 persisted after adjustment for the additional influence of sociodemographic and driving-related characteristics, particularly for the 2 statements regarding the implications of no longer driving (eg, $\mathrm{OR}=2.03,95 \% \mathrm{Cl}: 1.60$ 2.58 for high potential impact of driving cessation on what rural versus urban drivers need to do).

\section{Discussion}

Data from the AAA LongROAD Study cohort indicated that older drivers from a rural area were more likely to rate driving as highly important and the prospect of driving cessation as very impactful on their lives. As others have noted, these perceptions may influence older rural adults to continue driving despite the challenges posed by age-related decline in cognitive, sensory, and motor abilities. ${ }^{19}$ Subjective judgments about driving ability were included in a mail survey of adults 65 years of age or older in randomly selected households of 5 Midwestern and Western states. ${ }^{20}$ The sample was stratified by rurality using RuralUrban Continuum Codes $^{17}$ in order to examine urban-rural differences in attitudes about driving. Among the 775 respondents (412 rural, 363 urban) who stated that they were still driving, urban respondents were more likely than rural respondents to rate their driving ability as "excellent" (49\% vs. $40 \%$ ) and confidence in their driving ability as "very confident" (48\% vs. 38\%). These differences may have reflected underlying differences in the aforementioned physical and cognitive function of older rural and urban drivers. This comparison will be examined in future analyses of objective measures of functional status being collected in the AAA LongROAD Study. 
Adjustment for the sociodemographic and driving-related variables had little effect on the association between rural-urban status and the potential impact of driving cessation. For some characteristics related to potential impact (eg, gender, marital status, driving every day of the week, working for pay), adjustment had limited influence because these characteristics did not vary between urban and rural members of the LongROAD cohort. However, adjustment for the rural adults' lower levels of formal education, longer trips from home, and less use of public transportation did not account for the greater anticipated impact of driving cessation. Additional detail for some of these characteristics is likely needed to understand differences in the expected consequences of driving cessation. For example, while almost all participants reported a friend or family member was available to give them a ride, the degree and timing of availability for rides to certain destinations may not be comparable in rural and urban places. In a survey conducted at community presentations on road safety for older adults, Thompson and colleagues ${ }^{21}$ found that ruralurban differences in perceived importance of driving and transport options to common destinations varied significantly by specific destinations or reasons for importance.

\section{Limitations}

Limitations in these data should be noted. The 5 study sites were not chosen to be representative of urban, suburban, and rural places in the United States and therefore the findings may not be generalizable to settings that have different transportation-related resources and needs. As previously observed, ${ }^{16}$ the AAA LongROAD study population has relatively high levels of educational attainment and limited racial and ethnic diversity compared to the general older adult population. Furthermore, the study population was derived from the rosters of patients served by primary care clinics and health care systems at or near the study sites. While a sampling frame of active older drivers was not available, 
the finding that nearly $95 \%$ of US adults 65 years of age or older report having a personal doctor or health care provider indicates that this source may be a fairly representative option for this age group. ${ }^{22} \mathrm{~A}$ final limitation to acknowledge is that these data are based on current drivers' perceived impact of driving cessation in the future, and may not correspond to urban-rural differences in the actual impact of no longer driving.

\section{Conclusions}

The greater importance of driving and potential impact of driving cessation found in these data for older rural adults may require strategies to enhance both the ability to drive safely and the accessibility of alternative sources of transportation. Programs have been developed to improve driving ability through education about coping with high-risk conditions and situations; on-road training sessions; physical conditioning for better flexibility and range of motion; and use of driving simulators for visual processing speed training. ${ }^{23}$ Technological advances in driving support systems may also be particularly helpful for safety concerns of older rural adults (eg, poorly lit roads, narrow roads without shoulders, limited visibility of roadside objects and animals). ${ }^{9,24}$ Improvements in rural public transportation will be critical for reducing the impact of driving cessation. While the economic and logistical challenges for rural public transportation have been recognized, so have important strategic principles (eg, flexible services, interagency coordination and tailored outreach to potential riders) for addressing these challenges and meeting the transportation needs of the older rural adult population. ${ }^{25-27}$ 


\section{References}

1. Choi M, Lohman MC, Mezuk B. Trajectories of Cognitive Decline by Driving Mobility: Evidence from the Health and Retirement Study. Int I Geriatr Psychiatry. 2014;29(5):447-453.

2. Curl AL, Stowe JD, Cooney TM, Proulx C. Giving Up the Keys: How Driving Cessation Affects Engagement in Later Life. Gerontologist. 2014;54(3):423-433.

3. Doebler S. Access to a Car and the Self-Reported Health and Mental Health of People Aged 65 and Older in Northern Ireland. Res Aging 2016;38:453-476.

4. O'Connor ML, Edwards JD, Waters MP, Hudak EM, Valdes EG. Mediators of the Association between Driving Cessation and Mortality among Older Adults. Journal of Aging and Health 2013;25(8 suppl):249s-269s.

5. Tyrovolas S, Polychronopoulos E, Morena M, et al. Is Car Use Related with Successful Aging of Older Adults? Results from the Multinational Mediterranean Islands Study. Ann Epidemiol 2017;27:225-229.

6. Byles J, Gallienne L. Driving in Older Age: A Longitudinal Study of Women in Urban, Regional and Remote Areas and the Impact of Caregiving. J Women Aging 2012;24:113125.

7. Donorfio LK, D'Ambrosio LA, Coughlin JF, Mohyde M. To Drive or Not to Drive, This Isn't the Question - The Meaning of Self-Regulation among Older Drivers. J Safety Res 2009;40:221-226.

8. Johnson JE. Why Rural Elders Drive Against Advice. J Community Health Nurs 2002; 19(4):237-244.

9. Payyanadan RP, Lee JD, Grepo LC. Challenges for Older Drivers in Urban, Suburban and Rural Settings. Geriatrics 2018;3:14.

10. Boufous S, Finch C, Hayen A, Williamson A. The Impact of Environmental, Vehicle and Driver Characteristics on Injury Severity in Older Drivers Hospitalized as a Result of a Traffic Crash. J Safety Res 2008;39:65-72.

11. Thompson JP, Baldock MRJ, Mathias JL, Wundersitz LN. Older Drivers in Rural and Urban Areas: Comparison of Crash, Serious Injury and Fatality Rates. In Proceedings of the 2010 Australasian Road Safety Research, Policing and Education Conference. Canberra, Australia; 2010.

12. Thompson JP, Baldock MRJ, Mathias JL, Wundersitz LN. An Examination of the Environmental, Driver and Vehicle Factors Associated with the Serious and Fatal Crashes of Older Rural Drivers. Accid Anal Prev 2013;50:768-775.

13. Griffin LI. Older Driver Involvement in Injury Crashes in Texas, 1975-1999. Washington, DC: AAA Foundation for Traffic Safety; 2004.

14. Ross LA, Anstey KJ, Kiely KM, et al. Older Drivers in Australia: Trends in Driving Status and Cognitive and Visual Impairment. J Am Geriatr Soc 2009;57:1868-1873.

15. Keay L, Jasti S, Munoz B, et al. Urban and Rural Differences in Older Drivers' Failure to Stop at Stop Signs. Accid Anal Prev 2009;41:995-1000.

16. Li G, Eby DW, Santos R, et al. Longitudinal Research on Aging Drivers (LongROAD): Study Design and Methods. Inj Epidemiol. 2017;4:22.

17. Hall SA, Kaufman JS, Ricketts TC. Defining Urban and Rural Areas in US Epidemiologic Studies. J Urban Health. 2006;83(2):162-175.

18. Parker K, Horowitz JM, Brown A, Fry R, Cohn D, Igielnik R. What Unites and Divides Urban, Suburban and Rural Communities. Washington, DC: Pew Research Center; 2018. 
19. Owsley C. Driver Capabilities. In Transportation in an Aging Society: A Decade of Experience. Conference Proceedings 27. Washington, DC: Transportation Research Board; 2004.

20. Huseth A. Anticipatory Guidance Provision Related to Driving Safety/Cessation for Older Drivers: A Rural-Urban Comparison, MPC-14-277. North Dakota State University - Upper Great Plains Transportation Institute, Mountain-Plains Consortium, Fargo, ND; 2014.

21. Thompson JP, Baldock MRJ, Mathias JL, Wundersitz LN. Do Older Rural Drivers SelfRegulate their Driving? The Effects of Increased Driving Importance and Limited Alternative Transportation. J Australas Coll Road Saf. 2013b;24:30-42.

22. Centers for Disease Control and Prevention (CDC). BRFSS Prevalence \& Trends Data. Atlanta, GA: Centers for Disease Control and Prevention; 2017. https://www.cdc.gov/brfss/brfssprevalence/

23. Boot WR, Stothart C, Charness N. Improving the Safety of Aging Road Users: A MiniReview. Gerontology. 2014;60:90-96.

24. Eby DW, Molnar LJ, Zhang L, et al. Use, Perceptions and Benefits of Automotive Technologies among Aging Drivers. Injury Epidemiol. 2016;3:1-20.

25. Bond M, Brown JR, Wood J. Adapting to Challenge: Examining Older Adult Transportation in Rural Communities. Case Studies on Transport Policy. 2017;5:707-715.

26. Kostyniuk LP, St. Louis RM, Zanier N, et al. Transportation, Mobility and Older Adults in Rural Michigan. Lansing, MI: Office of Research and Best Practices, Michigan Department of Transportation; 2012.

27. Wood J, Brown JR, Bond M, Suguri V. Older Adult Transportation in Rural Communities: Results of an Agency Survey. J Public Trans. 2016;19:154-167.

Figure 1: Importance of Driving and Potential Impact of Driving Cessation by Older Adult Drivers from Urban, Suburban and Rural Areas: the AAA LongROAD Study

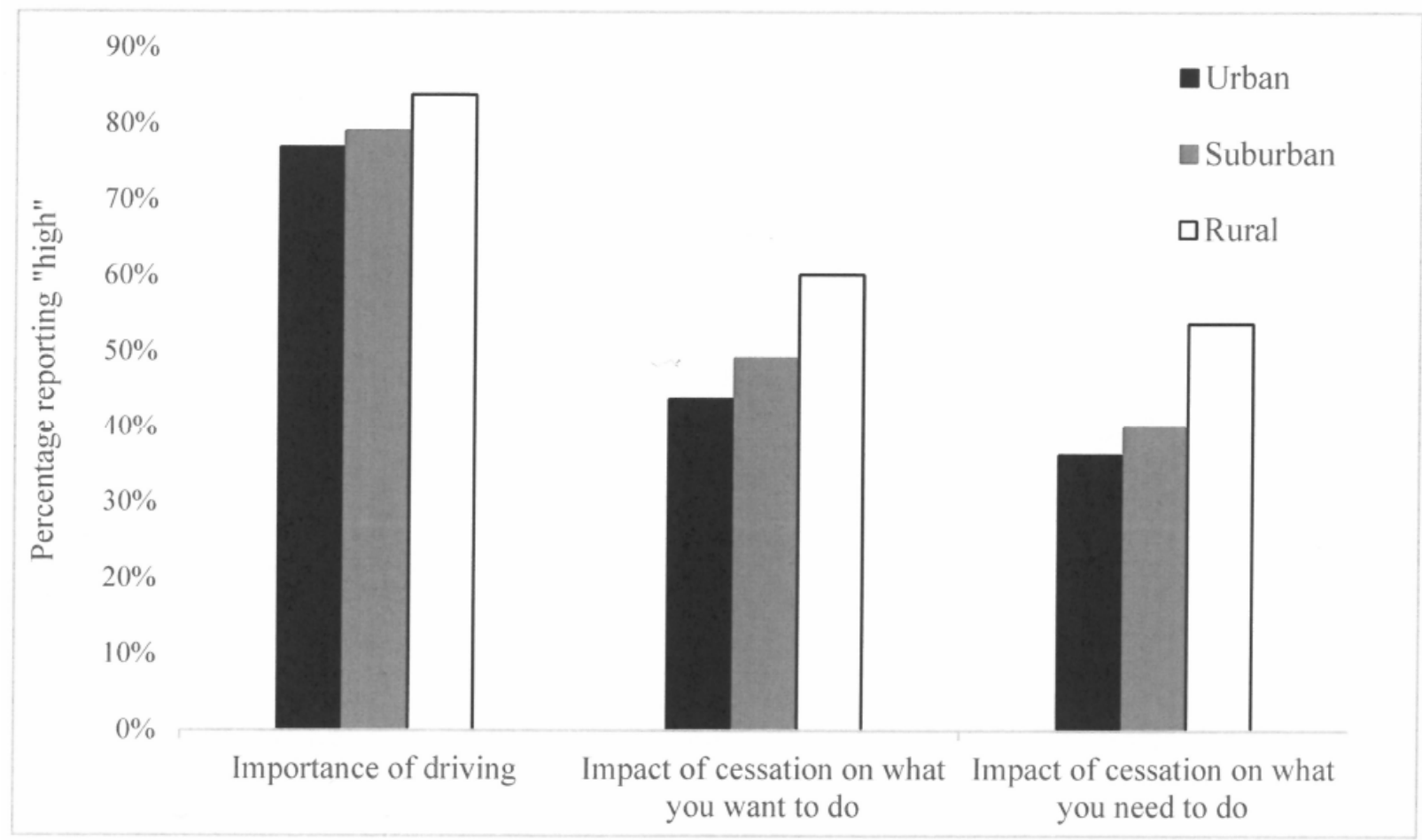

This article is protected by copyright. All rights reserved. 
Table 1. Sociodemographic and Driving-related Characteristics of Older Adult Drivers from Metropolitan and Non-Metropolitan Areas: the AAA LongROAD Study Cohort

\begin{tabular}{|c|c|c|c|}
\hline & $\begin{array}{c}\text { URBAN } \\
(\mathrm{N}=2,181)\end{array}$ & $\begin{array}{l}\text { SUBURBAN } \\
(\mathrm{N}=415)\end{array}$ & $\begin{array}{l}\text { RURAL } \\
(\mathrm{N}=394)\end{array}$ \\
\hline \multicolumn{4}{|l|}{ Sociodemographic Characteristics } \\
\hline Years of Age - mean (SD) & $71.0(4.1)$ & 71.4 (3.9) & $71.5(4.0)$ \\
\hline$\%$ Female & 53.0 & 51.8 & 54.8 \\
\hline \% Married or Living with Partner & 65.0 & 73.9 & 68.0 \\
\hline \% White, Non-Hispanic & 81.4 & 95.2 & 99.0 \\
\hline$\% \geq 16$ Years of Education & 68.9 & 48.7 & 55.9 \\
\hline$\%$ Income $\geq \$ 100,000$ & 37.7 & 22.3 & 20.1 \\
\hline \% Working for Pay & 31.3 & 26.7 & 28.4 \\
\hline \% Working as Volunteer & 46.0 & 44.2 & 48.0 \\
\hline \multicolumn{4}{|l|}{ Driving-related Characteristics } \\
\hline$\%$ Drive 7 days/week & 44.9 & 38.6 & 43.4 \\
\hline$\%$ Most trips from home $>15$ miles & 24.8 & 48.4 & 45.9 \\
\hline \multicolumn{4}{|l|}{ Used Forms of Transportation } \\
\hline$\%$ Public Bus in last 3 months & 13.7 & 6.3 & 7.1 \\
\hline$\%$ Train/Subway in last 3 months & 20.0 & 9.9 & 10.7 \\
\hline$\%$ Taxi in last 3 months & 18.9 & 8.4 & 9.6 \\
\hline \% Someone available to give me rides & 94.7 & 96.4 & 95.4 \\
\hline \% Someone depends on me for rides & 26.8 & 23.4 & 20.9 \\
\hline
\end{tabular}


Table 2. Logistic Regression Models for the Association of Sociodemographic Characteristics, Driving-Related Characteristics, and Rural/Urban Residence with the Importance of Driving and Potential Impact of Driving Cessation in Older Adult Drivers: the AAA LongROAD Study Cohort ${ }^{\mathrm{a}}$

$$
\text { VARIABLE (contrast) }
$$

\begin{tabular}{|c|c|c|c|}
\hline VARIABLE (contrast) & $\begin{array}{l}\text { Importance of } \\
\text { Driving } \\
\text { OR }(95 \% \mathrm{Cl})\end{array}$ & $\begin{array}{l}\text { Impact of Driving } \\
\text { Cessation on What } \\
\text { you Want to Do } \\
\text { OR }(95 \% \mathrm{Cl})\end{array}$ & $\begin{array}{l}\text { Impact of Driving } \\
\text { Cessation on What } \\
\text { you Need to Do } \\
\text { OR }(95 \% \mathrm{Cl})\end{array}$ \\
\hline \multicolumn{4}{|l|}{ SOCIODEMOGRAPHIC VARIABLES } \\
\hline Age (year) & $1.02(1.00-1.05)$ & $0.98(0.96-1.00)$ & $0.98(0.96-1.00)$ \\
\hline Gender (Female/Male) & $1.61(1.32-1.96)$ & $1.64(1.39-1.93)$ & $1.74(1.47-2.07)$ \\
\hline Race-Ethnicity (White,Non-Hispanic/other) & $1.29(1.00-1.68)$ & $1.03(0.82-1.29)$ & $0.86(0.68-1.08)$ \\
\hline Marital Status (Married, with Partner/other) & $0.79(0.63-0.99)$ & $0.79(0.66-0.94)$ & $0.73,(0.61-0.88)$ \\
\hline Education ( $\geq 16$ years $/<16$ years) & $1.05(0.85-1.29)$ & $0.77(0.65-0.92)$ & $0.73(0.61-0.87)$ \\
\hline Income $(\geq \$ 100,000 /<\$ 100,000)$ & $0.89(0.72-1.11)$ & $1.10(0.91-1.32)$ & $0.96(0.79-1.16)$ \\
\hline Working as Volunteer (yes/no) & $0.92(0.76-1.11)$ & $0.95(0.81-1.11)$ & $0.90(0.77-1.06)$ \\
\hline Working for Pay (yes/no) & $1.05(0.86-1.30)$ & $1.10(0.94-1.32)$ & $1.33(1.11-1.59)$ \\
\hline \multicolumn{4}{|l|}{ DRIVING-RELATED VARIABLES } \\
\hline Drive 7 days/week (yes/no) & $2.07(1.70-2.53)$ & $1.48(1.26-1.73)$ & $1.51(1.28-1.78)$ \\
\hline Most trips from home $>15$ miles (yes/no) & $1.31(1.06-1.63)$ & $1.22(1.03-1.45)$ & $1.31(1.10-1.56)$ \\
\hline Used bus in last 3 months (yes/no) & $0.69(0.52-0.91)$ & $0.78(0.60-1.01)$ & $0.71(0.54-0.94)$ \\
\hline Used train/subway in last 3 months (yes/no) & $0.80(0.62-1.03)$ & $0.80(0.64-1.01)$ & $0.79(0.62-1.01)$ \\
\hline Used taxi in last 3 months (yes/no) & $0.74(0.57-0.96)$ & $0.77(0.61-0.97)$ & $1.04(0.82-1.32)$ \\
\hline Someone available to give rides (yes/no) & $1.60(1.10-2.33)$ & $0.52(0.37-0.73)$ & $0.57(0.41-0.81)$ \\
\hline Someone depends on me for rides (yes/no) & $1.00(0.81-1.24)$ & $1.10(0.92-1.31)$ & $1.41(1.18-1.70)$ \\
\hline \multicolumn{4}{|l|}{ GEOGRAPHIC VARIABLES } \\
\hline RUCA Category (suburban/urban) & $0.97(0.73-1.29)$ & $1.15(0.91-1.45)$ & $1.13(0.89-1.44)$ \\
\hline RUCA Category (rural/urban) & $1.28(0.94-1.75)$ & $1.82(1.44-2.31)$ & $2.03(1.60-2.58)$ \\
\hline
\end{tabular}

${ }^{\mathrm{a}} P<.05$ for values with bold font 